\title{
ASSOCIATION OF HYPOTHYROIDISM WITH ABNORMAL UTERINE BLEEDING
}

\author{
Mishra Archana1, Jain Anita², Prakash Ritika³, Pandey Richa4
}

${ }^{1}$ Associate Professor, Department of Obstetrics and Gynaecology, Saraswati Medical College, Unnao, Kanpur. ${ }^{2}$ Assistant Professor, Department of Obstetrics and Gynaecology, Saraswati Medical College, Unnao, Kanpur. ${ }^{3}$ Senior Resident, Department of Obstetrics and Gynaecology, Saraswati Medical College, Unnao, Kanpur. ${ }^{4}$ Senior Resident, Department of Obstetrics and Gynaecology, Saraswati Medical College, Unnao, Kanpur. \begin{abstract}
\section{BACKGROUND}

Abnormal uterine bleeding is a very common presenting complaint in gynaecological OPD. So this study was conducted to find out the association of hypothyroidism in menstrual irregularity. Detecting and treating the thyroid abnormality will definitely reduce the incidence of hysterectomy done for menstrual irregularity. Menstrual disorders are a common problem during adolescence. These disorders may cause significant anxiety for patients and their families. Menorrhagia is a frequent debilitating symptom in gynaecological practice resulting in need for repeated curettage and hysterectomy with associated morbidity and mortality. The aetiology of abnormal menstrual bleeding is very diverse, it may be due to systemic conditions like endocrine disorders (Thyr oid dysfunction), or local lesions of the genital tract (Endometrial hyperplasia, pelvic inflammatory disease, endometriosis, benign and malignant tumours). Thyroid dysfunction is one of the most common cause of menstrual irregularities. There are established linkages between hypothyroidism and menstrual irregularities.

The objective of the study was to determine the frequency and type of menstrual irregularities associated with hypothyroidism. Menorrhagia and oligomenorrhoea were most commonly found in present study. Thus, it is concluded that menstrual irregularities increase with severity of hypothyroidism.
\end{abstract}

\section{MATERIALS AND METHODS}

A retrospective study was conducted in the Department of Obstetrics \& Gynaecology in Saraswati Medical College from October 2016 to September 2017. Total 200 patients who came to GYN OPD were taken. Out of which only 50 patients of age group 15 to 45 years were selected after complete clinical history, general and systemic examination and investigations.

\section{RESULTS}

In this research, total 200 patients were selected out of which 50 patients were observed for menstrual irregularity associated with hypothyroidism. The general problem was observed in age group 25-45 years. Menorrhagia and Oligomenorrhoea were the most common presenting symptoms. It was observed that menstrual irregularities were more frequent in patients with hypothyroidism.

\section{CONCLUSION}

We have seen in our study that menstrual irregularities increase with severity of hypothyroidism. Testing and treating hypothyroidism also avoids unnecessary hormonal treatment and hysterectomy surgeries. Most of the patients of hypothyroidism in reproductive age group present with menorrhagia in early stage of the disease.

\section{KEYWORDS}

Hypothyroidism, Abnormal Uterine Bleeding, Menorrhagia, Oligomenorrhoea.

HOW TO CITE THIS ARTICLE: Archana M, Anita J, Ritika P, et al. Association of hypothyroidism with abnormal uterine bleeding. J. Evolution Med. Dent. Sci. 2017;6(95):6957-6958, DOI: 10.14260/jemds/2017/1510

\section{BACKGROUND}

In gynaecological OPD, about $20 \%$ of women present with abnormal uterine bleeding.(1) It has been found that thyroid dysfunctions have profound effects on the female reproductive system.(2) Menstrual period is a part of ovarian cycle in which series of changes occurs in the ovary, uterus, vagina and breast every 28 days. (3) The normal menstrual pattern is governed by the hypothalamic-pituitary-ovarian axis via hormonal regulation and feedback loops. Thus, any disruption in this axis may result in menstrual cycle disturbances.(4) It is reported that abnormal uterine bleeding pattern occurs in different ways like oligomenorrhoea, polymenorrhoea, menorrhagia

'Financial or Other Competing Interest': None.

Submission 06-11-2017, Peer Review 07-12-2017,

Acceptance 14-12-2017, Published 25-12-2017.

Corresponding Author:

Dr. Archana Mishra,

C-385, Eldeco City, IIM Road, Lucknow-226013.

E-mail:drarchmish17@gmail.com

DOI: $10.14260 /$ jemds $/ 2017 / 1510$ and amenorrhea.(5) While activity of the thyroid is closely linked with the process of ovarian maturation, the thyroid gland is itself dependent on direct and indirect stimuli from the ovary to discharge its own function. During the investigations of abnormal uterine bleeding, abnormal sexual development, delayed puberty, hirsutism, infertility and recurrent pregnancy loss, the possibility of thyroid dysfunction must always be considered.

Most of the patients of hypothyroidism in reproductive age group present with menorrhagia in early stage of the disease. Endometrium is mostly proliferative and sometimes even atrophic. Urinary pregnanetriol levels are low which suggest failure of LH production, ovulation \& resultant menorrhagia. In later stages, secondary depression of pituitary occurs, leading to ovarian atrophy and amenorrhoea. The underlying aetiology of hypothyroidism commonly found is lymphocytic thyroiditis, thyroidectomy \& anti-thyroid drugs. Menorrhagia is the main symptom of hypothyroidism, its treatment with thyroxine has been demonstrated successfully. Thyrotoxicosis on the other hand presents mainly as hypomenorrhoea. Cycles 
may be shortened or prolonged and ultimately amenorrhoea develops. The aetiology of menstrual dysfunction in hypothyroidism is not known, whether it is primary effect of thyroid on ovary or uterus or mediated by primary dysfunction.

\section{Aim}

The aim of this study was to find out the hypothyroidism in women with menstrual irregularity.

\section{MATERIALS AND METHODS}

A retrospective study was conducted in the Department of Obstetrics \& Gynaecology in Saraswati Medical College from October 2016 to September 2017. Total 200 patients who came to GYN OPD were taken. Out of which only 50 patients of age group 15 to 45 years were selected after complete clinical history, general and systemic examination and investigations. Patients not included in the study were pregnant women, nursing mothers, patients not willing, above 45 years, below 15 years, menstrual irregularities due to other gynaecological problems. A prescribed proforma was designed to collect the relevant information. Complete clinical history of the patients was recorded in proforma that was collected from the records of the patient. All the patients who had other gynaecological problems were not included in the study group. Tests such as T3, T4, TSH, Hormone Profile \& Ultrasound Pelvis was done to rule out other causes of menstrual irregularities.

\section{RESULTS}

In this research, total 200 patients were selected out of which 50 patients were observed for menstrual irregularity associated with hypothyroidism. The general problem was observed in age group 25-45 years. Menorrhagia and Oligomenorrhoea were found as most common presenting symptoms. It was observed that menstrual irregularities were more frequent in patients with hypothyroidism.

\begin{tabular}{|c|c|c|c|}
\hline & Normal & Raised & Decreased \\
\hline T3 & $38(76 \%)$ & $4(8 \%)$ & $8(16 \%)$ \\
\hline T4 & $44(88 \%)$ & $3(6 \%)$ & $3(6 \%)$ \\
\hline TSH & $32(64 \%)$ & $11(22 \%)$ & $7(14 \%)$ \\
\hline \multicolumn{3}{|c|}{ Table 1. T3, T4 \& TSH Values IN AUB } \\
\hline
\end{tabular}

\begin{tabular}{|c|c|}
\hline Age Group (in years) & Hypothyroidism \\
\hline $15-24$ & $7(14.7 \%)$ \\
\hline $25-34$ & $12(20.58 \%)$ \\
\hline $35-45$ & $32(64.7 \%)$ \\
\hline \multicolumn{2}{|c|}{ Table 2. Age wise Distribution of Hypothyroidism } \\
\hline
\end{tabular}

\begin{tabular}{|c|c|c|c|}
\hline $\begin{array}{c}\text { Menstrual } \\
\text { Disorder }\end{array}$ & $\begin{array}{c}\mathbf{1 5 - 2 4} \\
\text { Years }\end{array}$ & $\begin{array}{c}\mathbf{2 5 - 3 4} \\
\text { Years }\end{array}$ & $\begin{array}{c}\mathbf{3 5 - 4 5} \\
\text { Years }\end{array}$ \\
\hline $\begin{array}{c}\text { Menorrhagia, } \\
\text { Polymenorrhoea }\end{array}$ & $4(8 \%)$ & $10(20 \%)$ & $25(50 \%)$ \\
\hline $\begin{array}{c}\text { Amenorrhoea, } \\
\text { Hypomenorrhoea }\end{array}$ & $5(10 \%)$ & $4(8 \%)$ & $2(4 \%)$ \\
\hline \multicolumn{4}{|c|}{ Table 3. Menstrual Disorders in Hypothyroidism } \\
\hline
\end{tabular}

\section{DISCUSSION}

We observed in our study that most of the hypothyroid patients detected with menstrual irregularities were in age group of 35 to 45 years. Pilli et al(6) also reported most of patients with abnormal menstrual disorders in age group of 21 to 40 years and only $2 \%$ below 20 years of age. Doefode \& Fernandes(7) reported $48.33 \%$ of patients with hypothyroidism in age group of 31 to 40 years having menstrual problem. According to Kris et al,(8) menorrhagia and oligomenorrhoea are the common menstrual irregularities in hypothyroidism which is same as noted in the present study. Menon \& Bharucha( ${ }^{9)}$ gave an incidence of $46.15 \%$ of menorrhagia and $23.07 \%$ of oligomenorrhoea that matches our results.

Normal ovarian function requires normal levels of thyroid hormone. Deficiency of thyroid hormone causes direct suppression of ovaries resulting in menstrual irregularities.

\section{CONCLUSION}

All women presenting with menstrual abnormalities should be tested for thyroid functions. Also, those presenting with thyroid dysfunction must be screened for menstrual disorders. We have seen in our study that menstrual irregularities increase with severity of hypothyroidism. Testing and treating hypothyroidism also avoids unnecessary hormonal treatment and hysterectomy surgeries.

\section{REFERENCES}

[1] Nesse RE. Abnormal vaginal bleeding in perimenopausal women. Am family physician 1989;40(1):185-92.

[2] Berek JS, Adarsh EY, Hillard PA. Endocrine disorders. Novak's Gynecology. 12th edn. 2001:864.

[3] Mohan S, Page LM, Higham JM. Diagnosis of abnormal uterine bleeding. Best Pract Res Clin Obstet Gynaecol 2007;21(6):891-903.

[4] Popat VB, Prodanov T, Calis KA, et al. The menstrual cycle: a biological marker of general health in adolescents. Ann N Y Acad Sci 2008;1135:43-51.

[5] Singh BB, Berman BM, Simpson RL, et al. Incidence of premenstrual syndrome \& remedy usage: a national probability sample study. Altern Ther Health Med 1998;4(3):75-9.

[6] Pilli GS, Sethi B, Dhaded AV, et al. Dysfunctional uterine bleeding. J Obstet \& Gynaec India 2001;52(3):87-9.

[7] Doifode CD, Fernandes K. Study of thyroid dysfunction in patient with DUB. J Obst Gynae India 2001;51(2):935.

[8] Poppe K, Velkeniers B, Glinoer D. The role of thyroid autoimmunity in fertility and pregnancy. Nature Clinical Practice Endocrinology \& Metabolism 2008;4(7):394-405.

[9] Menon VK, Barucha KE. Menstrual dysfunction \& thyroid disease. J Obst Gynae India 1995;45(4):521-6. 